Original Research Paper

\title{
Spectral and Luminescence Properties of Manganese Doped Sodium Lead Alumino Borosilicate Glass System
}

\author{
${ }^{1 *}$ K. Vijaya Babu, ${ }^{2}$ A. Subba Rao, ${ }^{3}$ K. Naresh Kumar and ${ }^{2}$ M. Venugopala Rao \\ ${ }^{1 *}$ Department of Physics, Bapatla College of Arts and Sciences, Bapatla, India \\ ${ }^{2}$ Department of Physics, SS \& N College, Narasaraopet, India \\ ${ }^{3}$ Department of Physics, VRS \& YRN College, Chirala, India
}

\author{
Article history \\ Received: 27-06-2019 \\ Revised: 28-10-2019 \\ Accepted: 22-11-2019 \\ Corresponding Author: \\ Dr. Karumuri Vijaya Babu \\ Department of Physics, \\ Bapatla College of Arts and \\ Sciences, Bapatla, A.P, India \\ Email: kamalavijay007@gmail.com
}

\begin{abstract}
Na}_{2} \mathrm{O}-\mathrm{PbO}-\mathrm{Al}_{2} \mathrm{O}_{3}-\mathrm{B}_{2} \mathrm{O}_{3}-\mathrm{SiO}_{2}$ glasses mixed with different concentrations of $\mathrm{MnO}$ (ranging from 0.3 to $0.9 \mathrm{~mol} \%$ ) was prepared by melt quenching technique. The samples were characterized by $\mathrm{X}$-ray diffraction technique, Optical absorption and Photo luminescence technique. A prepared glass sample is confirmed by X-ray diffraction spectra. The optical absorption spectra of these glasses exhibited a predominant broad band peak at $21,052 \mathrm{~cm}^{-1}(475 \mathrm{~nm})$ is identified due to ${ }^{6} \mathrm{~A}_{\mathrm{lg}}(\mathrm{S}) \rightarrow{ }^{4} \mathrm{~T}_{\mathrm{gg}}(\mathrm{G})$ octahedral transition of $\mathrm{Mn}^{2+}$ ion. From the spectral analysis the optical band gap $\left(\mathrm{E}_{\mathrm{opt}}\right)$ and Urbach energy $(\Delta \mathrm{E})$ are evaluated. The emission spectra of $\mathrm{Mn}^{2+}$ doped titled glasses have shown single and broad emission band at about $600 \mathrm{~nm}$ assigned to electronic transition ${ }^{4} \mathrm{~T}_{1 \mathrm{~g}}(\mathrm{G}) \rightarrow{ }^{6} \mathrm{~A}_{1 \mathrm{~g}}(\mathrm{~S})$ displaying red emission upon excitation at $413 \mathrm{~nm}$. Various principle physical properties were also evaluated.
\end{abstract}

Keywords: Borosilicate Glass, Melt Quenching Method, XRD, Optical and Luminescence Studies

\section{Introduction}

Borosilicate glasses have wide range of technological applications in various fields such as solar energy technology, optoelectronics, sealing glasses, nuclear waste immobilization and also as construction materials. More over these materials have good optical clarity, for this reason they are used as lens in high quality flash lights and astronomical reflecting telescope in micro electrochemical systems (Santhan Kumar et al., 2013; Wen and Tanner, 2015; Varshneya, 1994; Pfaerder, 1996; Wan et al., 2014; Ruengsri et al., 2012; Laopaiboon and Bootlomchai, 2015; Bootjomchai et al., 2014; Limbach et al., 2015).

Sodium alumino borosilicate glass results from the combination of network-forming oxides with the network modifier $\mathrm{Na}_{2} \mathrm{O}$, intermediate oxides, $\mathrm{PbO}$ and $\mathrm{Al}_{2} \mathrm{O}_{3}$. The addition of $\mathrm{Na}_{2} \mathrm{O}$ reduces the melting temperature and facilitates the homogenization of the glass system, reducing defects and bubbles (Poli Reddy et al., 2014; Serqueira et al., 2011; Saini et al., 2009; ElBatlal et al., 2007). The intermediate oxide, $\mathrm{PbO}$ introduced into titled glasses which results structural changes by strong influence of the local network due to its several properties such as low melting temperature, high density, high refractive index that improves the chemical durability and enhance the resistance against diversification. These materials are used as metal seals, ceramic sealants and nuclear radiation shielding windows (Khanna et al., 2013; Nagesh et al., 1983; Kothiyal, 2004; El-Kameesy et al., 2013; Biswas et al., 2010; Chen et al., 2012) etc. $\mathrm{Al}_{2} \mathrm{O}_{3}$ can act as network former as well as modifier and enhance the glass forming ability, chemical durability and thermal stability.

An addition of small amount of $\mathrm{MnO}$ to borosilicate glasses facilitates the enhancement in mechanical, optical, electrical properties. Manganese ions have strong bearing on the optical, magnetic and electrical properties of glasses. These ions can exist in different valence states with different co-ordinations in glass matrices, for example as $\mathrm{Mn}^{3+}$ in borate glasses with octahedral coordination whereas in silicate and germinate glasses as $\mathrm{Mn}^{2+}$ with both tetrahedral and octahedral environment. $\mathrm{Mn}^{3+}$ and $\mathrm{Mn}^{2+}$ ions are well known paramagnetic ions. $\mathrm{Mn}^{2+}$ ion have half filled $\mathrm{d}$ orbital with $\mathrm{d}^{5}$ configuration and ${ }^{6} \mathrm{~S}$ as the ground state, for these reasons, the total orbital angular momentum for $\mathrm{Mn}^{2+}$ ion is zero. Since the total spin is $5 / 2$, this ion exhibits zero field splitting which is sensitive to the local environment. The $\mathrm{Mn}^{3+}$ ion have a large magnetic anisotropy due to its strong spin-orbit interaction of the 3d orbital whereas $\mathrm{Mn}^{2+}$ ion have small anisotropy 
energy due to its zero orbital angular momentum. The objectivity of the present investigation is to have a comprehensive understanding over the local environment of manganese ion in $\mathrm{Na}_{2} \mathrm{O}-\mathrm{PbO}-\mathrm{Al}_{2} \mathrm{O}_{3}-\mathrm{B}_{2} \mathrm{O}_{3}-\mathrm{SiO}_{2}$ glass system, by a systematic study of various physical parameters, coupled with optical absorption and luminescence investigations.

\section{Experimental Methods}

$\mathrm{Na}_{2} \mathrm{O}-\mathrm{PbO}-\mathrm{Al}_{2} \mathrm{O}_{3}-\mathrm{B}_{2} \mathrm{O}_{3}-\mathrm{SiO}_{2}: \mathrm{MnO}$ doped glasses were prepared by using melt-quenching technique. The dopant ion concentration in the glass composition is between from 0.3 to $0.9 \mathrm{~mol} \%$. The chemical compositions of the present study are listed in Table 1. The AR reagents of raw materials $\left(\mathrm{Na}_{2} \mathrm{O}, \mathrm{PbO}, \mathrm{Al}_{2} \mathrm{O}_{3}\right.$, $\mathrm{B}_{2} \mathrm{O}_{3}, \mathrm{SiO}_{2}$ and $\mathrm{MnO}$ of $99.99 \%$ purity) were powdered and thoroughly mixed in an agate mortar. The mixture was taken in a silica crucible placed in an automatic temperature controlled furnace at a temperature $1200^{\circ} \mathrm{C}$ for $20 \mathrm{~min}$ until a bubble-free liquid is obtained. This liquid was pored on a pre-heated brass mold to the room temperature and subsequently annealed at $400^{\circ} \mathrm{C}$ for $8 \mathrm{~h}$ to reduce thermal stress and increase the mechanical strength of the material. The prepared samples were optically polished. Final dimensions of the samples used for the present study are $1 \times 1 \times 0.1 \mathrm{~cm}$.

\section{Characterization Techniques}

The optical absorption spectra were recorded on a JASCO UV-VIS-NIR spectrophotometer (Model V-670) at room temperature in the range $200-2000 \mathrm{~nm}$. The Xray powder diffraction pattern of prepared glass samples were recorded using on XRD-6100 SHIMADZU X-ray diffractometer in the scanning range of $10-80^{\circ}(2 \theta)$ using $\mathrm{Cu} \mathrm{K}_{\alpha}$ radiation having a wavelength of $1.5406 \AA$ at room temperature. The photoluminescence spectra were recorded at room temperature on the fluorescence spectrometer (SPEX Flouorolog-3) using a 450W Xelamp as the excitation source.

\section{Measurements}

The density for the glasses was measured by using Archimedes principle with $\mathrm{O}$-xylene as immersion liquid. The weights of the prepared glass samples were measured in air and $\mathrm{O}$-xylene using a 4- digit sensitive microbalance. Then the density ( $\rho)$ was determined from the relation:

$$
\rho=\frac{w_{1}}{w_{1}-w_{2}} \times d
$$

where, ' $w_{1}$ ' is the weight in air, ' $w_{2}$ ' is the weight in Oxylene and ' $d$ ' is the density of O-xylene.
Table 1: Glass compositions of MnO doped NPABS glass system

\begin{tabular}{lllllll}
\hline Glass & & & & & & \\
Code & $\mathrm{Na}_{2} \mathrm{O}$ & $\mathrm{PbO}$ & $\mathrm{Al}_{2} \mathrm{O}_{3}$ & $\mathrm{~B}_{2} \mathrm{O}_{3}$ & $\mathrm{SiO}_{2}$ & $\mathrm{MnO}$ \\
\hline Pure & 20 & 10 & 5.0 & 40 & 25 & - \\
$\mathrm{M}_{1}$ & 20 & 10 & 4.7 & 40 & 25 & 0.3 \\
$\mathrm{M}_{2}$ & 20 & 10 & 4.4 & 40 & 25 & 0.6 \\
$\mathrm{M}_{3}$ & 20 & 10 & 4.1 & 40 & 25 & 0.9 \\
\hline
\end{tabular}

The corresponding molar volume $\left(V_{M}\right)$ was calculated using the relation:

$$
V_{M}=\frac{M_{T}}{\rho}
$$

where, $M_{T}$ is the total molecular weight of the multicomponent glass system.

The refractive index was measured at $\lambda=589.3 \mathrm{~nm}$ on Abbe's Refractometer with monobromonaphthalene as the constant layer between the sample and prism of a refractometer by using sodium vapor lamp as the source and average molecular weight (M), Optical basicity have been evaluated (Meejitpaisn et al., 2012; Kaewjaeng et al., 2012; Sreehari Sastry et al., 2014). The theoretical values for optical basicity of the glass were estimated using the formula:

$$
\Lambda_{t h}=\sum_{i=1}^{n} \frac{z_{i} r_{i}}{2 \gamma_{i}}
$$

where, $n$ is total number of cations present, $Z_{i}$ for oxidation number of the $i_{t h}$ cation, $r_{i}$ ratio of number of $i_{t h}$ cation to the number of oxides present and $\gamma_{i}$ basicity moderating parameter of the $i^{t h}$ cation. The basicity moderating parameter $\gamma_{i}$ was calculated from the following equation:

$$
\gamma_{\mathrm{i}}=1.36\left(x_{\mathrm{i}}-0.26\right)
$$

where, $x_{i}$ is the Pauling electro negativity of the cation.

\section{Results and Discussion}

\section{XRD Studies}

From the Fig. 1 the XRD spectra of all the prepared glass samples show no crystalline sharp Bragg's peak, but only a broad hump around lower angle region. This is indication of amorphous nature of the prepared glass samples (Naresh and Buddhudu, 2012).

\section{Physical Parameters}

The physical properties of prepared glasses are very interesting and provide useful information regarding the structure and transmission mechanism due to transport of ions. The density of glass is one of the most important 
properties in manufacturing glass production and it is required for calculating the properties of refractive index. The measured values of density and physical parameters such as dopant ion concentration $\left(N_{i}\right)$, mean separation $\left(r_{i}\right)$, refractive index and optical basicity of these prepared glasses are given in Table 2. The progressive introduction of $\mathrm{MnO}$ has causes enhance in density of the samples, the degree of structural compactness, the modification of geometrical configuration of the glassy network (Singh et al., 2012).

\section{Optical Absorption Studies}

The optical band gap of these glasses has been computed based on their optical absorption spectra for understanding their optically induced transitions. There are two types of transitions, which can occur at the fundamental absorption edge of glass materials. They are direct and indirect transitions. In both cases, electromagnetic waves interact with the electrons in the valence band, which rise across the fundamental band gap to the conduction band. The optical absorption coefficient $(\alpha)$ of a material can be evaluated from the optical transmittance and reflectance using the relation:

$$
\alpha(v)=1 / d \ln ((1-R) / T)
$$

where, ' $\mathrm{d}$ ' is the thickness of the prepared glass sample, while the absorption coefficient $\alpha(v)$ as a function of photon energy (hv) for direct and indirect optical transitions, according to Pankove (1971) is given by:

$$
\alpha h v=A\left(h v-E_{g}\right)^{n}
$$

where, ' $\mathrm{A}$ ' is a constant and $\mathrm{E}_{\mathrm{g}}$ is the band gap energy and the exponent ' $n$ ' take the values $1 / 2$ or 2 for allowed direct or indirect transitions, respectively. To estimate the optical energy band gap values for direct or indirect transitions $(\alpha h v)^{1 / 2}$ and $(\alpha h v)^{2}$ as a function of 'hv' have been plotted. The respective values of the band gap energies can be obtained by extrapolating the linear portion of the plot for $(\alpha h v)^{1 / 2}=0$ for indirect transition, the optical band for indirect transition values varies from $4.040-3.664 \mathrm{eV}$ and $(\alpha \mathrm{hv})^{2}=0$ for direct transitions, whose values vary from $4.053-3.656 \mathrm{eV}$. The optical band gap energies decrease with the increase of manganese ion concentration. Also Urbach energy values increases from $0.249-0.275 \mathrm{eV}$ with the increase of manganese ion concentration as shown in Fig. 2a to 2c (Pal et al., 2011).

Table 2: Physical parameters of MnO doped NPABS glass

\begin{tabular}{lllll}
\hline & \multicolumn{4}{c}{ Sample code } \\
System & -------------------------------- \\
Parameters & Pure & $\mathrm{M}_{1}$ & $\mathrm{M}_{2}$ & $\mathrm{M}_{3}$ \\
\hline Density $(\rho) \mathrm{gcm}^{-3}$ & 2.960 & 2.981 & 2.989 & 2.999 \\
Molar volume $\left(\mathrm{V}_{\mathrm{m}}\right)$ & 29.854 & 29.629 & 29.526 & 29.411 \\
Ion conc. $\left(\mathrm{N}_{\mathrm{i}}\right) \times 10^{20}$ & - & 0.611 & 1.228 & 1.858 \\
Ionic radius $\left(\mathrm{r}_{\mathrm{i}}\right) \AA$ & - & 25.8 & 20.4 & 17.8 \\
Polaron radius $\left(\mathrm{r}_{\mathrm{p}}\right) \AA$ & - & 10.236 & 8.116 & 7.081 \\
Refractive index $\left(\mathrm{n}_{\mathrm{d}}\right)$ & 1.653 & 1.654 & 1.655 & 1.656 \\
Optical basicity $\left(\Lambda_{\mathrm{th}}\right)$ & 0.429 & 0.431 & 0.432 & 0.439 \\
\hline
\end{tabular}

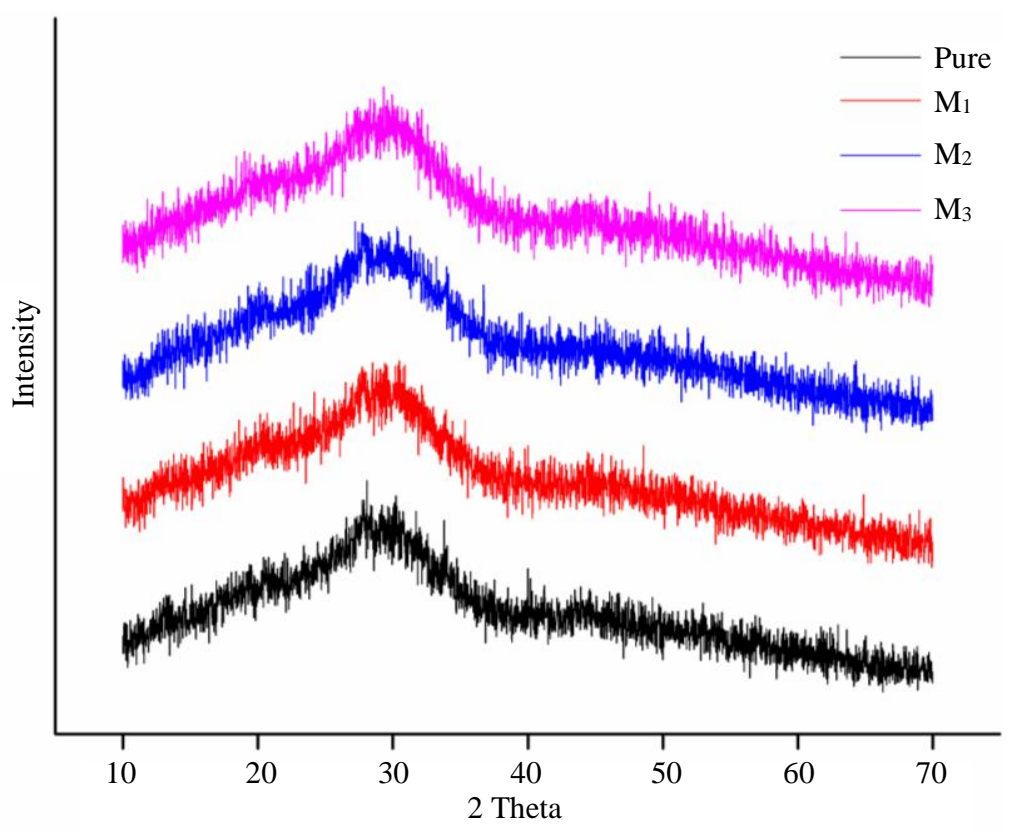

Fig. 1: XRD pattern of MnO doped NPABS glasses 
The absorption spectra of transition metal ions are influenced by the nature of the host matrices into which those ions are accommodated owing to the excitation spectra of $3 \mathrm{~d}$ electrons. The absorption spectra of transition metal ions are fairly broader and sensitive to the changes in coordination and symmetry. Due to the presence of various oxidation states, each of the states can give an increase to different absorption spectra which can be explained by the application of ligand field theory. Figure $2 \mathrm{c}$ shows, the optical spectra of NPABS: MnO glasses in the wavelength region $300-700 \mathrm{~nm}$. The absorption edge appeared at $305 \mathrm{~nm}$ for pure glass $\mathrm{M}_{0}$ is shifted slightly towards to higher wavelengths with increasing concentration of $\mathrm{MnO}$. The spectrum of these glasses has exhibited a broad absorption band at $480 \mathrm{~nm}$ corresponding to the transition ${ }^{6} \mathrm{~A}_{1 \mathrm{~g}}(\mathrm{~S}) \rightarrow{ }^{4} \mathrm{~T}_{1 \mathrm{~g}}(\mathrm{G})$ of $\mathrm{Mn}^{2+}$ ions. This band is identified due to the octahedral transition of $\mathrm{Mn}^{2+}$ ions (Meejitpaisn et al., 2012a; Jaya Raja et al., 2014). The optical absorption spectra of $\mathrm{Na}_{2} \mathrm{O}-\mathrm{PbO}-\mathrm{Al}_{2} \mathrm{O}_{3}-\mathrm{B}_{2} \mathrm{O}_{3}-\mathrm{SiO}_{2}$ : $\mathrm{MnO}$ glasses are presented in Table 3 .

\section{Photoluminescence Studies}

Luminescence characteristics are very sensitive and the complex property mainly depends on the spin and parity forbidden transitions of electronic configuration and also on the local structure of luminescent species which is affected by the surrounding matrix. Figure 3 shows emission spectra of sodium lead alumino borosilicate (NPABS) glasses. The excitation spectrum exhibiting a couple of bands at $367 \mathrm{~nm}$ and $413 \mathrm{~nm}$ is assigned to d-d transitions of ${ }^{6} \mathrm{~A}_{1 \mathrm{~g}}(\mathrm{~S}) \rightarrow{ }^{4} \mathrm{~T}_{2 \mathrm{~g}}(\mathrm{D})$ and ${ }^{6} \mathrm{~A}_{1 \mathrm{~g}}(\mathrm{~S}) \rightarrow{ }^{4} \mathrm{~T}_{1 \mathrm{~g}}(\mathrm{D})+{ }^{4} \mathrm{E}_{1 \mathrm{~g}}(\mathrm{G})$. From the excitation spectrum,

The band at $413 \mathrm{~nm}$ has been chosen to measure emission spectra of MnO: NPABS glasses. Upon exciting at $413 \mathrm{~nm}$, manganese ions in ground are excited to upper ligand field status there upon they relax non radiatively from these localized states to ${ }^{4} \mathrm{~T}_{1 \mathrm{~g}}(\mathrm{G})$ state through ${ }^{4} \mathrm{E}_{1 \mathrm{~g}}(\mathrm{D}),{ }^{4} \mathrm{~T}_{2 \mathrm{~g}}(\mathrm{D}),\left({ }^{4} \mathrm{E}_{1 \mathrm{~g}},{ }^{4} \mathrm{~A}_{1 \mathrm{~g}}\right)(\mathrm{G})$ and ${ }^{4} \mathrm{~T}_{2 \mathrm{~g}}(\mathrm{G})$ intermediate energy levels and decay radiately to ${ }^{6} \mathrm{~A}_{1 \mathrm{~g}}(\mathrm{~S})$ state via phonon emission generating a broad red emission band around $600 \mathrm{~nm}$ assigned to a spin forbidden transition of ${ }^{4} \mathrm{~T}_{1 \mathrm{~g}}(\mathrm{G}) \rightarrow$ ${ }^{6} \mathrm{~A}_{1 \mathrm{~g}}(\mathrm{~S})$ with a inversion symmetry. The emission spectra of $\mathrm{Mn}^{2+}$ doped glasses are broad indicating broad distribution of $\mathrm{Mn}^{2+}$ sites and sensitive to change in coordination and symmetry. Generally, the emission spectra of $\mathrm{Mn}^{2+}$ ion depending on its coordination number, ligand field strength and also on the host composition of the titled glass. $\mathrm{Mn}^{2+}$ ion in tetrahedral environment exhibits emission in green region while $\mathrm{Mn}^{2+}$ ion in octahedral environment is in the red region. In the present case, spectral position of emission band peaking at $600 \mathrm{~nm}$ exhibiting red emission having six coordination number with strong ligand field strengths confirms the octahedral site symmetry of $\mathrm{Mn}^{2+}$ (Rupesh Kumar et al., 2013; ElAhdal et al., 2011; Samsudin et al., 2016; Peng et al., 2016; Naresh and Bhuddhudu, 2013).

Figure 4 shows CIE diagram of $\mathrm{MnO}$ doped in sodium lead alumino borosilicate glasses. In order to inspect the quality of light, Color Correlated Temperature (CCT) values have been calculated from colour coordinates using McCamy empirical formula (Mccamy, 1992):

$$
C C T=-437 n^{3}+3601 n^{2}-6861 n+5514.31
$$

where, $n=\left(x-x_{e}\right) /\left(y-y_{e}\right)$ and the chromaticity epicenters is at $x_{e}=0.3320$ and $y_{e}=0.1858,(x, y)$ are the calculated coordinates of prepared samples. The evaluated CIE coordinates are denoted as $(x=0.4759$, $y=0.4477),(x=0.4749, y=0.4488)$ and $(x=0.4879$, $y=0.4508)$ respectively. CCTs of $\mathrm{MnO}$ doped NPABS glasses range between 2770-2707 K respectively. Generally, CCT value greater than 5000 $\mathrm{K}$ indicates the cold white light used for commercial lighting purpose and less than $5000 \mathrm{~K}$ indicates the warm white light used for home appliances (Lee et al., 2006; Murphy Jr, 2014; Ambast et al., 2014). The color intensity coordinates of CIE are mentioned in Table 4 along with CCT values, CIE coordinates also acclaim that these glasses are suitable for red emission. Hence, $\mathrm{MnO}$ doped NPABS glasses emits a near warm white light emission.

Table 3: Summary of data on optical absorption of $\mathrm{MnO}$ doped NPABS glass system

\begin{tabular}{lllll}
\hline & & \multicolumn{3}{c}{ Band gap energy $(\Delta \mathrm{E})(\mathrm{eV})$} \\
Glass & Band position $(\mathrm{nm})$ & $-\mathrm{-}-\mathrm{-}-\mathrm{-}$ \\
code & ${ }^{6} \mathrm{~A}_{1 \mathrm{~g}}(\mathrm{~S}) \rightarrow{ }^{4} \mathrm{~T}_{1 \mathrm{~g}}(\mathrm{G})$ & Direct & Indirect & Urbach \\
\hline Pure & ---- & 4.053 & 4.040 & 0.249 \\
$\mathrm{M}_{1}$ & 474.5 & 3.959 & 3.911 & 0.257 \\
$\mathrm{M}_{2}$ & 476 & 3.722 & 3.709 & 0.271 \\
$\mathrm{M}_{3}$ & 477 & 3.656 & 3.664 & 0.275 \\
\hline
\end{tabular}

Table 4: Glass label, chromaticity coordinates (x, y) and Correlated Color Temperature (CCT) for various $\mathrm{Mn}^{2+}$ : NPABS Glass systems

\begin{tabular}{llll}
\hline & \multicolumn{3}{c}{ Chromaticity } \\
& ------------------ & \\
Glass label & x & y & CCT (K) \\
\hline NPABSM $_{1}$ & 0.4759 & 0.4477 & 2770 \\
NPABSM $_{2}$ & 0.4749 & 0.4488 & 2743 \\
NPABSM $_{3}$ & 0.4879 & 0.4508 & 2707 \\
\hline
\end{tabular}




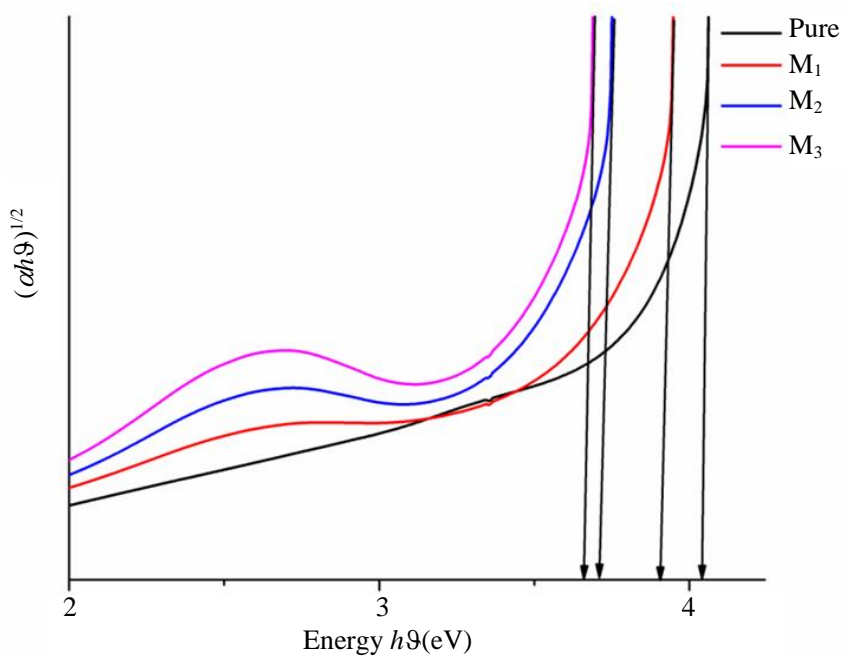

(a)

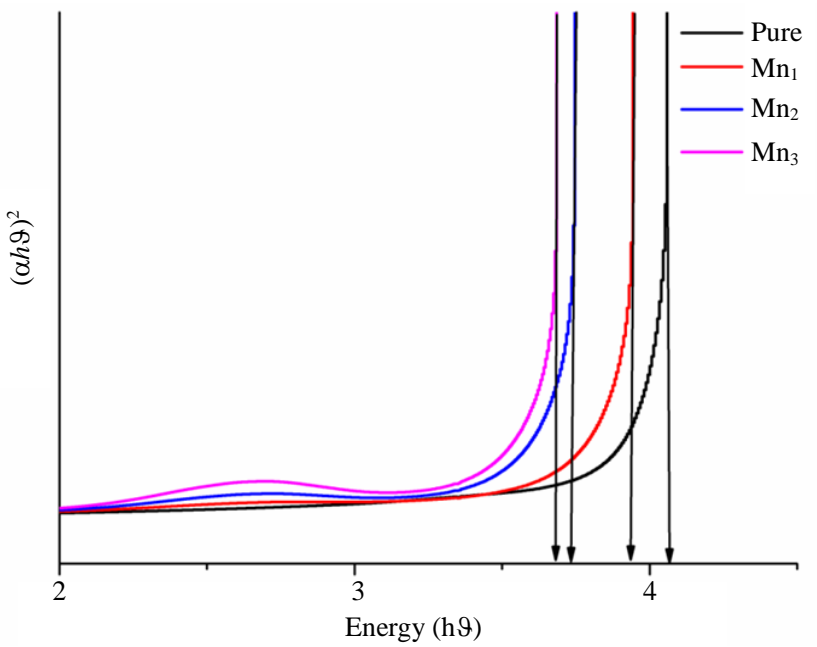

(b)

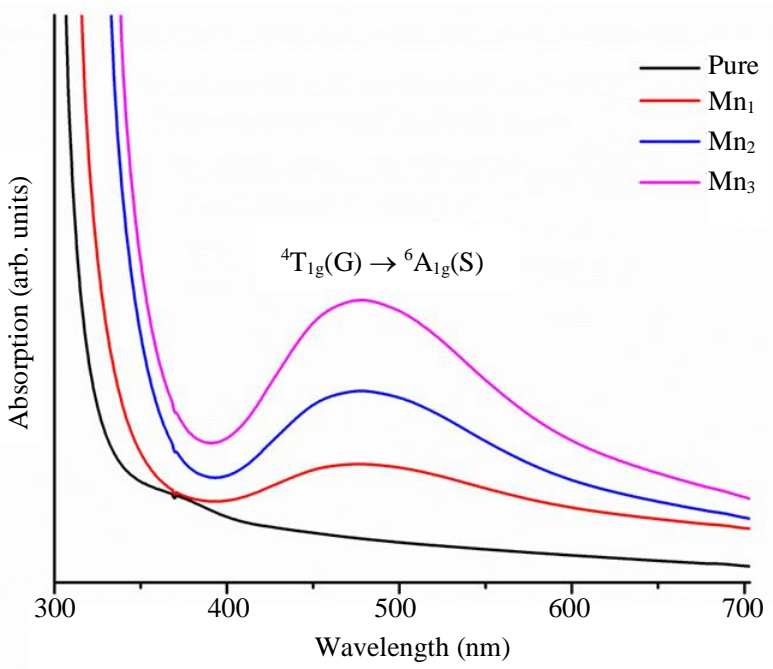

(c)

Fig. 2: (a) Indirect plots to evaluate optical band gap of MnO doped NPABS glasses; (b) Direct plots to evaluate optical band gap of $\mathrm{MnO}$ doped NPABS glasses; (c) Optical absorption spectra of MnO doped NPABS glasses 


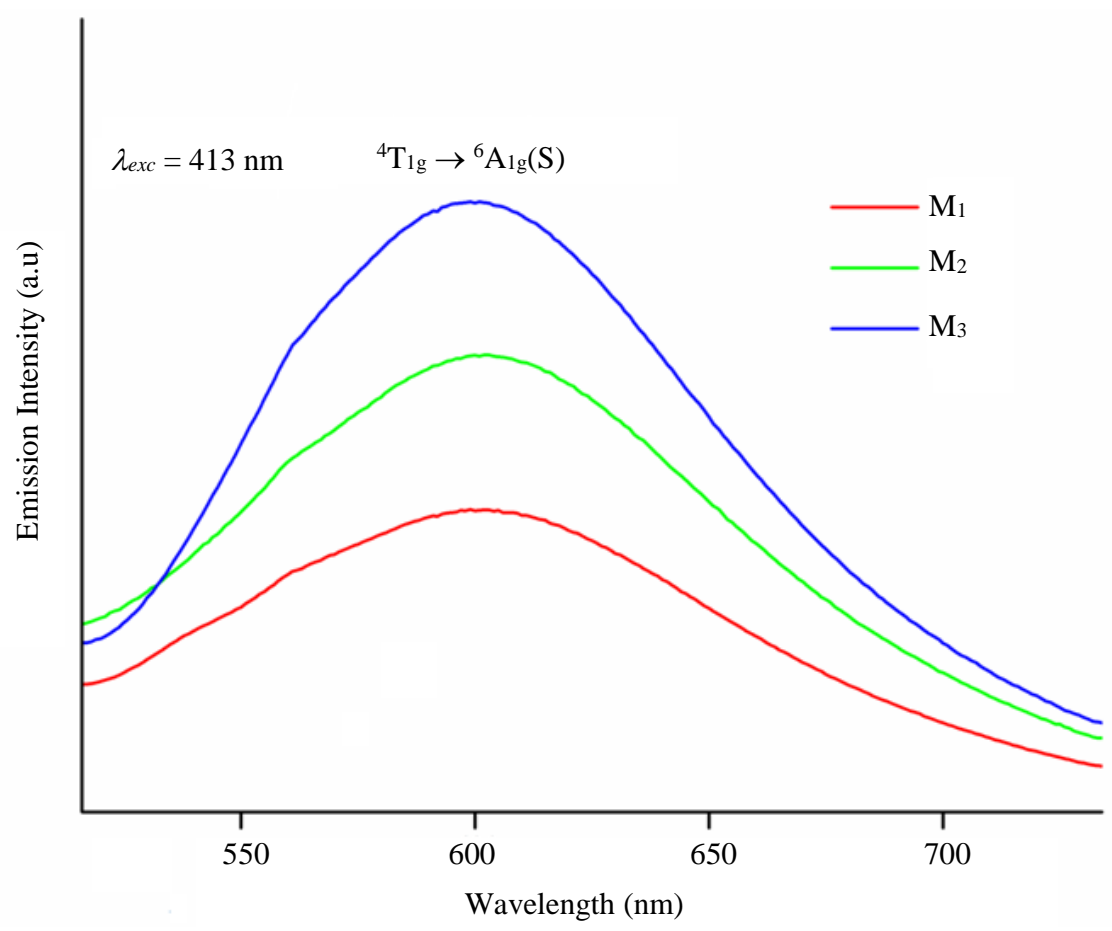

Fig. 3: Emission spectra of MnO doped NPABS glasses

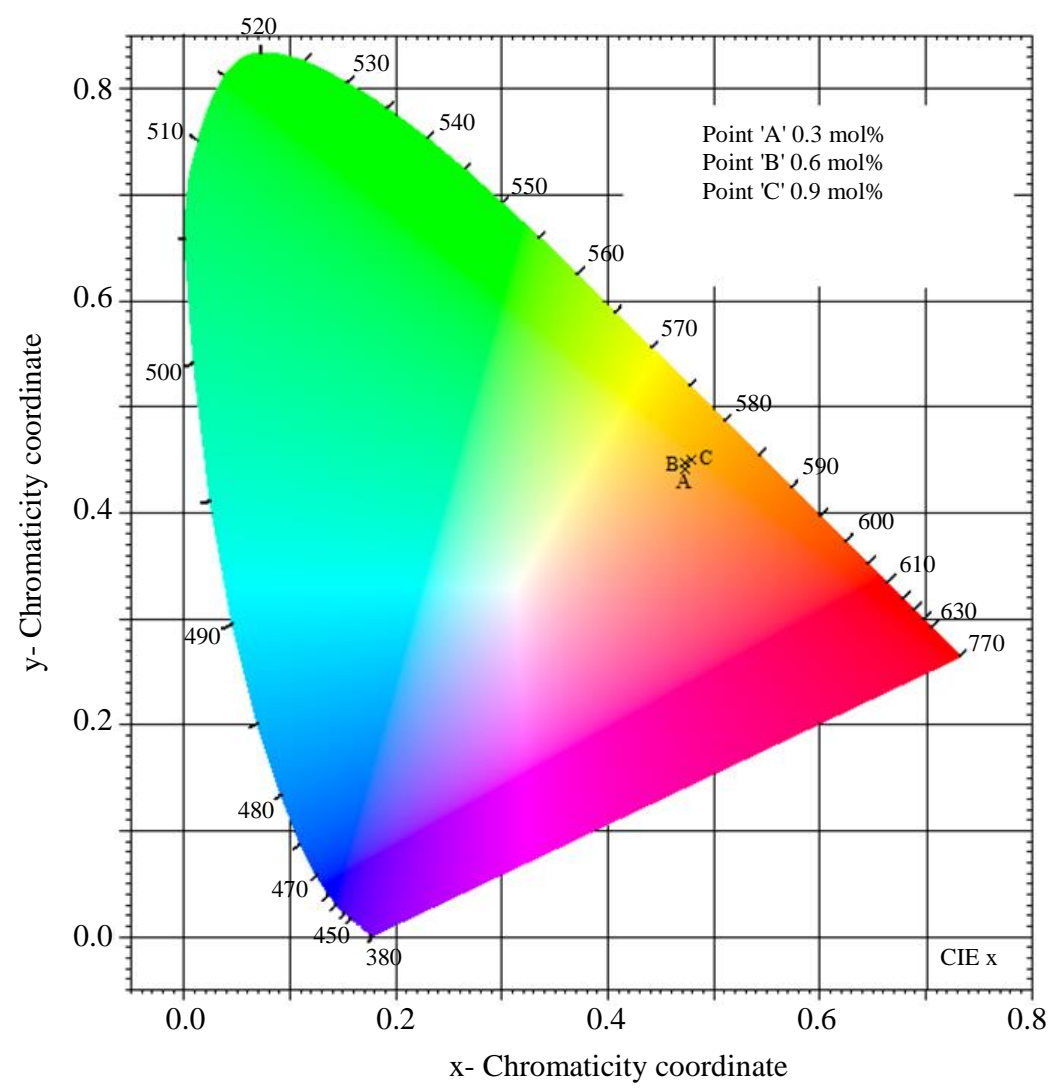

Fig. 4: 1931 CIE color chromaticity diagram of the $\mathrm{Mn}^{2+}$ doped NPABS glasses 


\section{Conclusion}

The conclusion drawn from studying various properties of $\mathrm{Na}_{2} \mathrm{O}-\mathrm{PbO}-\mathrm{Al}_{2} \mathrm{O}_{3}-\mathrm{B}_{2} \mathrm{O}_{3}-\mathrm{SiO}_{2}$ glasses doped with manganese ions are as follows:

Amorphous nature of the samples is confirmed by the broad diffused haloes in XRD pattern. The density and refractive index of the samples are found to increase with increasing concentration. Optical absorption spectra of these glasses exhibits a predominant broad band peak at about $475 \mathrm{~nm}$ is identified due to ${ }^{6} \mathrm{~A}_{1 \mathrm{~g}}(\mathrm{~S})$ $\rightarrow{ }^{4} \mathrm{~T}_{1 \mathrm{~g}}(\mathrm{G})$ octahedral transition of $\mathrm{Mn}^{2+}$ ion. $\mathrm{MnO}$ doped NPABS glasses have displayed a broad red emission band at $600 \mathrm{~nm}$ assigned to a spin forbidden transition of ${ }^{4} \mathrm{~T}_{1 \mathrm{~g}}(\mathrm{G}) \rightarrow{ }^{6} \mathrm{~A}_{1 \mathrm{~g}}(\mathrm{~S})$. The CIE chromaticity color coordinates calculated from emission spectra of $\mathrm{Mn}^{2+}$ doped NPABS glasses show that the glasses emit warm white light. The band position of manganese emission confirms $\mathrm{Mn}^{2+}$ state in octahedral position having six coordination numbers with strong crystal field strength. From this observation it is concluded that the $\mathrm{Mn}^{2+}$ ions predominately occupy octahedral positions in this glass network.

\section{Acknowledgement}

The authors are thankful to the DST-FIST, New Delhi for sanctioning equipment to the Department of Physics, Acharya Nagarjuna University to carry out the present research work.

\section{Author's Contributions}

All authors equally contributed in this work.

\section{Ethics}

This is my own work, after the publication of this paper; if any ethical issues maybe arise I will have answered.

\section{References}

Ambast, A.K., J. Goutam, S. Som and S.K. Sharma, 2014. $\mathrm{Ca}_{1-\mathrm{x}-\mathrm{y}} \mathrm{Dy}_{\mathrm{x}} \mathrm{KyWO}_{4}$ : A novel near UV converting phosphor for white light emitting diode. Spectrochim. Acta A, 122: 93-99.

Biswas, K., A.D. Sontakke and K. Annapurna, 2010. Effect of $\mathrm{TiO}_{2}$ on thermal, structural and third-order nonlinear optical properties of Ca-La-B-O glass system. J. Alloy Compds, 489: 493-498.

Bootjomchai, C., R. Laopaiboon, S. Pencharee and J. Laopaiboon, 2014. Elastic moduli of borosilicate glasses doped with heavy metal oxides. J. NonCryst. Solids, 388: 37-45.
Chen, Q., Q. Chen and M. Ferraris, 2012. Effect of ceramic crucibles on magneto-optical $\mathrm{PbO}-\mathrm{Bi}_{2} \mathrm{O}_{3}-$ $\mathrm{B}_{2} \mathrm{O}_{3}$ glasses properties. New J. Glass Ceram., 2: 41-50.

El-Ahdal, M.A., E.M. Antar, H.H. Mahmoud and F.M. Ezz-Eldin, 2011. ESR and infrared studies of gamma-irradiated lead-phosphate glasses doped with $\mathrm{MnO}_{2}$. J. Applied Sci. Reason, 7: 1434-1441.

El Batlal, F.H., M.S. Selim, S.Y. Marzouk and M.A. Azooz, 2007. UV-vis absorption of the transition metal-doped $\mathrm{SiO}_{2}-\mathrm{B}_{2} \mathrm{O}_{3}-\mathrm{Na}_{2} \mathrm{O}$ glasses. Phys. B, 398: 126-134.

El-Kameesy, S.Y., S.A. El-Ghany, M.A. El-Hakam Azooz and Y.A. Allah El-Gammam, 2013. Shielding properties of lead zinc borate glasses. World J. Phys. Conden Matter, 3: 198-202.

Jaya Raja, B., M. Rajesh Yadav, V. Pushpa Manjari, B. Babu and C. Rama Krishna et al., 2014. Synthesis and characterization of undoped and $\mathrm{Mn}$ (II)ions doped $\mathrm{Li}_{2} \mathrm{CaAl}_{4}\left(\mathrm{PO}_{4}\right)_{4} \mathrm{~F}_{4}$ nanophosphors. J. Mol. Struct., 1076: 461-467.

Kaewjaeng, S., J. Kaewkhao, P. Limsuwan and U. Maghanemi, 2012. Effect of $\mathrm{BaO}$ on optical, physical and radiation shielding properties of $\mathrm{SiO}_{2}$ $\mathrm{B}_{2} \mathrm{O}_{3}-\mathrm{Al}_{2} \mathrm{O}_{3}-\mathrm{CaO}-\mathrm{Na}_{2} \mathrm{O}$ glass system. Proc. Eng., 32: 1080-1086.

Khanna, A., A. Saini, B.C. FernandomGonzalez, C. Pesquera, 2013. Stryctural study of bismuth borosilicate, aluminoborate and aluminoborosilicate glasses by $11 \mathrm{~B}$ and $27 \mathrm{Al}$ MAS NMR spectroscopy and thermal analysis. J. Non-Cryst. Solids, 373: 34-41.

Kothiyal, G.P., 2004. Preparation and studies of structural and thermo-mechanical aspects of some special glasses and glass-ceramics. Bhabha Atomic Res. Centre News Lett., 249: 123-133.

Laopaiboon, R. and C. Bootlomchai, 2015. Physical properties and thermo luminescence of glasses designed for radiation dosimetry measurements. Mater. Des., 80: 20-27.

Lee, S.H., J.H. Park, S.M. Son and J.S. Kim, 2006. White-light-emitting phosphor: $\mathrm{CaMgSi}_{2} \mathrm{O}_{6}: \mathrm{Eu}^{2+}$, $\mathrm{Mn}^{2+}$ and itsrelated properties with blending. Applied Phys. Lett., 89: 221916.

Limbach, R., A. Winterstein-Beck Mann, J. Dellith, D. Moncke and L. Wondraczek, 2015. Plasticity, Crack initation and defect resistance in alkali-borosilicate glasses: From normal to anomalous behavior. J. Non-Cryst. Solids, 417: 15-27.

Mccamy, C.S., 1992. Correlated color temperature as an explicit function of chromaticity coordinates. Colour Res. Applied, 17: 142-144.

Meejitpaisn, P., J. Kaewkhao, P. Limsuwan and C. Kedkaew, 2012. Physical and optical properties of the SLS glass doped with low $\mathrm{Cr}_{2} \mathrm{O}_{3}$ concentrations. Procedia Eng., 32: 787-792. 
Murphy Jr, T.W., 2014. Maximum spectral luminous efficacy of white light. J. Applied Phys., 111: 104909-104909.

Nagesh, V.K., A.P. Tomsia and J.A. Pask, 1983. Wetting reaction in the lead borosilicate glass-precious metal system. J. Mater. Sci., 18: 2173-2180.

Naresh, V. and Buddhudu, 2012. Studies on optical, dielectric and magnetic properties of $\mathrm{Mn}^{2+}, \mathrm{Fe}^{3+}$ and $\mathrm{Co}^{2+}$ ions doped lfbcd glasses. Ferroelectr. Rev., 437: 110-125.

Naresh, V. and S. Bhuddhudu, 2013. Luminescence, electrical and magnetic studies of $\mathrm{Mn}^{2+}: \mathrm{Li}_{2} \mathrm{O}-\mathrm{LiF}-$ $\mathrm{B}_{2} \mathrm{O}_{3}-\mathrm{CdO}$ glasses. AIP Conf. Proc.

Pal, M., B. Roy and M. Pal, 2011. Structural characterization of borate glasses containing zinc and manganese oxides. Int. J. Mod. Phys., 2: 1062-1066.

Pankove, J., 1971. Optical Processes in Semiconductors. 1st Edn., Englewood Cliffs, ISBN-10: 0486602753, pp: 422.

Peng, M., X. Yin, P.A. Tanner, M.G. Brik and P. Li, 2016. Site occupancy preference, enhancement mechanism and thermal resistance of $\mathrm{Mn}^{4+}$ redluminescence in $\mathrm{Sr}_{4} \mathrm{Al}_{14} \mathrm{O}_{25}: \mathrm{Mn}^{4+}$ for warm LEDs. Chem. Mater., 27: 2938-2945.

Pfaerder, H.G., 1996. Schott Guide to Glass. 1st Edn., Springer, Netherlands, ISBN-13: 978-94-011-0517-0, pp: 224.

Poli Reddy, V., T.G.V.M. Rao, A. Rupesh Kumar, K. Neeraja and K. Kalyan Chakravarthi et al., 2014. Optical and structural analysis of $\mathrm{Ho}^{3+}$ ion doped sodium zirconium silicate gasses. Int. J. Current Eng. Technol.

Ruengsri, S., J. Kaewkhao and P. Limsuwan, 2012. Optical characterization of soda lime borosilicate glass doped with tio2. Proc. Eng., 32: 772-779.

Rupesh Kumar, A., T.G.V.M. Rao, N. Veeraiah and M. Rami Reddy, 2013. Fluorescence spectroscopic studies of $\mathrm{Mn}^{2+}$ Ions in $\mathrm{SrO}-\mathrm{Al}_{2} \mathrm{O}_{3}-\mathrm{B}_{2} \mathrm{O}_{3}-\mathrm{SiO}_{2}$ glass system. Opt. Mater, 35: 402-406.
Saini, A., A. Khanna, V.K. Michaelis, S. Kroeker and F. González et al., 2009. Structure -property correlations in lead borate and borosilicate glasses doped with aluminum oxide. J. Non- Cryst. Solids, 355: 2323-2332.

Samsudin, N.F., K.A. Matori, Z.A. Wahab, J.Y.C. Liew and Y.W. Fen et al., 2016. Low cost phosphors: Structural and photoluminescence properties of $\mathrm{Mn}^{2+}$-doped willemite glass-ceramimcs. Optik, 127: 8076-8081. DOI: 10.1016/j.ijleo.2016.06.019

Santhan Kumar, J., V. Madhuri, J. Lakshmi Kumari and sandhya Cole, 2013. Spectral studies of vanady 1doped cadmium strontium borosilicate glass system. Applied Magnetic Reson., 44: 479-494.

Serqueira, E.O., N.O. Dantas and M.J.V. Bell, 2011. Control of spectroscopic flurescence parameters of $\mathrm{Nd}^{3+}$ ions as a function of concentration in $\mathrm{SiO}_{2-}$ $\mathrm{Na}_{2} \mathrm{O}-\mathrm{Al}_{2} \mathrm{O}_{3}-\mathrm{B}_{2} \mathrm{O}_{3}$ glass system. Chem. Phys. Lett., 508: 125-129.

Singh, G.P., P. Kaur, S. Kaur, D. Arora and P. Singh et al., 2012. Density and FT-IR studies of multiple transition metal doped borate glass. Mater. Phys. Mech., 14: 31- 36.

Sreehari Sastry, S., S. Vedavyas and B. Rupa Venkateswara Rao, 2014. Physical and optical properties of $\mathrm{Mn}$ (II) doped $\mathrm{P}_{2} \mathrm{O}_{5}-\mathrm{ZnO}-\mathrm{CaO}$ glasses. Int. J. Innovative Res. Sci. Eng. Technol., 3: 1146-1151.

Varshneya, A.K., 1994. Fundamentals of Inorganic Glasses, 1st Edn., Gulf Professional Publishing, ISBN-10: 0127149708, pp: 570.

Wan, M.H., P.S. Wong, R. Hussin, H.O. Lintang and S. Endud, 2014. Structural and luminescence properties of $\mathrm{Mn}^{2+}$ ions doped calcium zinc borophosphate glasses. J. Alloys Compd., 595: 39-45.

Wen, H. and P.A. Tanner, 2015. Optical properties of 3rd transition metal ion-doped sodium borosilicate glass. J. Alloys Compd., 625: 328-335. 